\title{
Relationship between pigment production and haemolysin formation by Lancefield group $B$ streptococci
}

\author{
J. W. TAPSALL
}

Department of Microbiology, The Prince of Wales Hospital, Randwick, Sydney, New South Wales, 2031 Australia

\begin{abstract}
Summary. Group B streptococci produce both a pigment and a haemolysin. The requirements of group $B$ streptococci for the formation and release of pigment and haemolysin are similar and have been examined to extend observations on the relationship between the two products. The amount of pigment and haemolysin extractable from actively metabolising washed-cell suspensions of group B streptococci varied with the atmosphere of incubation, the $p \mathrm{H}$ at which the extraction was carried out and the presence of $\mathrm{Mg}^{2+}$ ions. Both pigment and haemolysin were produced in significant amounts in all phases of the growth cycle. When conditions were established for obtaining maximum yields of haemolysin, its production correlated closely with pigment yields, but pigment did not function as a carrier for haemolysin. Formation of pigment, but not of haemolysin, increased in the presence of trimethoprim or higher concentrations of glucose. The composition of pigment produced in different conditions differed qualitatively and different strains of group B streptococci formed pigment of different appearance, suggesting that group B streptococcal pigment is composed of several different substances.
\end{abstract}

\section{Introduction}

Most Lancefield group B streptococci form an orange-red pigment when grown in appropriate conditions. The ability to produce pigment appears to be related to the ability to release a haemolysin in that non-haemolytic strains usually lack pigment (Noble et al., 1983) and the simultaneous loss of both properties has been recorded either as a spontaneous event (Lancefield, 1934) or after exposure to mutagens (Wennerstrom et al., 1985). Similarities have also been observed in the formation of these two products in vitro. Marchlewicz and Duncan (1980), using washed-cell suspensions of group B cells, demonstrated the formation and extracellular release of haemolysin by an active metabolic process. They also found that for haemolysin release a suitable carrier molecule is required and that this carrier stabilises the haemolysin. Pigment is formed and released under similar conditions (Tapsall, 1986), also by an active metabolic process, and a suitable carrier is required to complete the release of pigment and to stabilise extracellular pigment. The natural carrier of the haemolysin has been shown to be lipoteichoic acid

Received 17 Jul. 1986; accepted 18 Sep. 1986.
(Tsaihong and Wennerstrom, 1983) and the pigment is located in the cell membrane (Merritt and Jacobs, 1978).

This study extended observations on the formation of pigment and haemolysin in vitro by group B streptococci and examined further the relationship between them. The effect of physical and chemical variables that influence the extracellular release of haemolysin and pigment have been investigated and compared, and the yields of each from a number of strains whose haemolytic properties on blood agar differ have been measured.

\section{Materials and methods}

\section{Organisms}

The strains of group B streptococci used were: the pigment-producing strain NCTC 8017 (type III) and the non-pigmented variant NCTC 8020 as a control. Strain NCTC 11360 (type Ia) and clinical isolates B1 (type Ibc), 3C (type Ibc) and 3321 (type Ib) were used to compare haemolysin and pigment production.

\section{Culture media and growth conditions}

Todd-Hewitt Broth (Oxoid) modified by the addition of Neopeptone (Difco) $1 \% \mathrm{w} / \mathrm{v}$ and phosphate buffer 
$\left(\mathrm{Na}_{2} \mathrm{HPO}_{4} .2 \mathrm{H}_{2} \mathrm{O}, 0.074 \mathrm{~g} / \mathrm{L}\right.$ and $\mathrm{NaH}_{2} \mathrm{PO}_{4} .2 \mathrm{H}_{2} \mathrm{O}$, $0.013 \mathrm{~g} / \mathrm{L}$ ) (THB) was used; 50 -ml amounts seeded from cultures grown overnight at $37^{\circ} \mathrm{C}$ on horse-blood agar were incubated in an atmosphere of $\mathrm{CO}_{2} 5 \%$ in air at $37^{\circ} \mathrm{C}$.

\section{Haemolysin formation, release and measurement}

Organisms were grown in THB to the late exponential phase of growth (c. 5h) and the turbidity of the culture adjusted, by adding uninoculated THB, to an optical density of 0.6 on a Bausch and Lomb Spectronic 20 spectrophotometer.

In certain experiments, volumes of THB greater than $50 \mathrm{ml}$ were incubated and harvested at different phases of the growth cycle from early exponential phase to late stationary phase. The turbidity of these cultures was also adjusted to an optical density of 0.6 either by centrifuging the culture and resuspending it in a smaller volume of supernate, or by diluting the culture with uninoculated THB.

Twenty ml of the culture was centrifuged, the supernate discarded, the cell pellet washed in phosphate-buffered

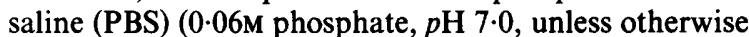
specified), and resuspended in $2.5 \mathrm{ml}$ of extractor fluid. This contained soluble starch (BDH) $1 \% \mathrm{w} / \mathrm{v}$ and Tween 80 (Sigma) $3 \% \mathrm{v} / \mathrm{v}$ in PBS with glucose $1 \% \mathrm{w} / \mathrm{v}$ (Marchlewicz and Duncan, 1980). In certain experiments the $p \mathrm{H}$ of the PBS solution was in the range $6 \cdot 2-7 \cdot 8$ and the phosphate concentration lowered to $0.01 \mathrm{M} . \mathrm{Mg}^{2+}$ was added to the extractor solution as $\mathrm{MgSO}_{4}$ in concentrations from 10 to $100 \mathrm{~mm}$. Trimethoprim lactate (Roche, Sydney, Australia) was added to the extractor solution to provide concentrations of trimethoprim base of 2.5 $10 \mathrm{mg} / \mathrm{L}$, and glucose was used in concentrations of 1 $10 \% \mathrm{w} / \mathrm{v}$.

Washed cells in the extractor solution were incubated in air for $30 \mathrm{~min}$ at $37^{\circ} \mathrm{C}$ (unless otherwise specified) when the reaction was stopped by placing them in an icewater bath. The mixture was then centrifuged and the amount of haemolysin in the supernate measured as follows. Serial twofold dilutions of the supernate in $0.5 \mathrm{ml}$ of PBS were mixed with an equal volume of a $1 \%$ suspension of thrice washed sheep erythrocytes (Commonwealth Serum Laboratories, Melbourne, Australia) and incubated for $30 \mathrm{~min}$ at $37^{\circ} \mathrm{C}$; unlysed erythrocytes were then removed by brief centrifugation and the haemoglobin present in the supernate determined by measuring the absorbance at $540 \mathrm{~nm}$ with a Stasar III spectrophotometer (Gilford). One haemolytic unit (HU) was defined as the amount of haemolysin in $0.5 \mathrm{ml}$ of the solution which, in the above conditions, lysed half of the sheep erythrocytes. Haemolysin production in anaerobic conditions was measured in a Kaltec SJ3 anaerobic chamber (Edwardston, South Australia) containing an atmosphere of $\mathrm{N}_{2} \quad 90 \%$ and $\mathrm{CO}_{2} \quad 10 \%$. The extractor solution and the bacterial cell pellet were placed in the chamber $30 \mathrm{~min}$ before mixing. After incubation for $30 \mathrm{~min}$, the amount of haemolysin present was measured as described above.

\section{Pigment formation, release and measurement}

Washed cell pellets were prepared as for haemolysin production and pigment then extracted by incubating the cells in a solution of PBS with added glucose $1 \% \mathrm{w} / \mathrm{v}$, $10 \mathrm{mM} \mathrm{Mg}{ }^{2+}$ and soluble starch $0 \cdot 1 \% \mathrm{w} / \mathrm{v}$ for $30 \mathrm{~min}$ at $37^{\circ} \mathrm{C}$ (Tapsall, 1986). The cell suspension was then centrifuged and the absorbance of the supernate determined, at wavelengths of $520,485,455$ and $435 \mathrm{~nm}$, with a Pye-Unicam SP 1800 spectrophotometer. In some experiments the composition of the extractor fluid was altered by increasing the glucose content over a range up to $10 \% \mathrm{w} / \mathrm{v}$; in others, trimethoprim lactate was added to provide trimethoprim base in concentrations from 2.5 to $15 \mathrm{mg} / \mathrm{L}$. Pigment formation in anaerobic conditions was also examined in conditions identical to those used for anaerobic production of haemolysin and as described previously (Tapsall, 1986).

\section{Relationship between haemolysin and pigment}

Pigment was examined for its ability to act as a carrier for haemolysin. Four-peak and single-peak pigment solutions were prepared from the strain NCTC 8017 (Tapsall, 1986) and the haemolytic activity present was assessed. Glucose $1 \% \mathrm{w} / \mathrm{v}$ and $20 \mathrm{mM} \mathrm{Mg}{ }^{2+}$ in PBS were added to these, which were then used as extractor solutions. Another extractor fluid was prepared from the non-pigmented strain NCTC 8020 in a similar fashion and control solutions included a PBS- $\mathrm{Mg}^{2+}$ solution with and without starch-Tween 80 .

\section{Results}

\section{Haemolysin formation}

Haemolysin was present in haemolysin-extractor supernates, but was absent or greatly reduced if glucose or starch and Tween 80 were omitted from the extractor solution. Adding $\mathbf{M g}^{2+}$ to the solution in concentrations of $10 \mathrm{~mm}$ or more increased yields of haemolysin but adding trimethoprim did not (table I). In subsequent experiments, $20 \mathrm{mM} \mathrm{Mg}^{2+}$ was added to the extractor solution. No increase in haemolysin production was observed either with increased glucose concentration or in anaerobic conditions (table I).

Haemolysin was produced in increasing amounts during incubation for up to $45 \mathrm{~min}$, after which no further increase occurred. The $p \mathrm{H}$ of the extractor solution measured after various incubation times is shown in table II. When $0.01 \mathrm{M}$ PBS replaced the usual 0.06M PBS, less haemolysin was formed and the maximum yield was obtained after incubation for $15 \mathrm{~min}$. The final $p \mathrm{H}$ of these modified extractor fluids was lower and was reached after shorter incubation periods (table II). Changing the $p \mathrm{H}$ of 
Table I. Haemolysin formation by cells of group B streptococcus strain NCTC 8017 incubated in different extractor solutions

\begin{tabular}{lc}
\hline Conditions of extraction & $\begin{array}{c}\text { Haemolysin } \\
\text { titre }(\mathrm{HU})\end{array}$ \\
\hline Initial procedure* & 690 \\
Deletion of: & \\
Starch and Tween 80 & 1 \\
Glucose & \\
Addition of: & \\
$\mathrm{Mg}^{2+}(\mathrm{mM}):$ & 845 \\
10 & 920 \\
$20-100$ & 620 \\
Trimethoprim $10 \mathrm{mg} / \mathrm{L}$ & 920 \\
$\mathrm{Mg}^{2+}(20 \mathrm{mM})$ and $\mathrm{Trimethoprim}(\mathrm{mg} / \mathrm{L}):$ & 890 \\
$2 \cdot 5$ & 830 \\
5 & 840 \\
10 & 685 \\
Glucose $8 \%$ and $20 \mathrm{~mm} \mathrm{Mg}^{2+}$ & \\
Anaerobic extraction: & \\
$20 \mathrm{mM} \mathrm{Mg}^{2+}$, glucose $1 \%$ & \\
\hline
\end{tabular}

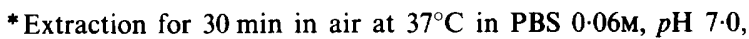
containing starch $1 \% \mathrm{w} / \mathrm{v}$, Tween $803 \% \mathrm{w} / \mathrm{v}$ and glucose $1 \%$ $\mathbf{w} / \mathrm{v}$.

PBS used to wash cell pellets and in extractor fluids over the range $7 \cdot 8-7 \cdot 0$ did not change the amount of haemolysin produced, but less haemolysin was formed when PBS with a lower $p \mathrm{H}$ was used (table II). When a cell pellet which had been used to produce haemolysin in the standard conditions described was rewashed in PBS and resuspended in fresh extractor solution, haemolysin was produced in the same amounts as before. A progressive loss of haemolytic activity was noted when haemolysin preparations were stored at $37^{\circ} \mathrm{C}$, activity being reduced by approximately $10 \%$ after $60 \mathrm{~min}$.

Cells at all stages of the growth cycle produced haemolysin. At equivalent optical density, cells harvested at any time from mid-exponential phase to early stationary phase produced equivalent amounts of haemolysin. About $10 \%$ less was produced by cells harvested in the early exponential and late stationary phases.

\section{Pigment production}

Pigment was released into the extractor solution and formed absorbance peaks at 520, 485, 455 and $435 \mathrm{~nm}$ on spectrophotometric analysis. When trimethoprim was added to the extractor solution in concentrations of $2 \cdot 5-10 \mathrm{mg} / \mathrm{L}$, pigment yields increased (table III). The highest yields were obtained with a concentration of $2.5 \mathrm{mg} / \mathrm{L}$ but concentrations of trimethoprim above $10 \mathrm{mg} / \mathrm{L}$ decreased the amount of pigment produced. Furthermore, the type of pigment produced differed with different concentrations of trimethoprim. The increase in the amount of pigment produced with trimethoprim $2.5 \mathrm{mg} / \mathrm{L}$ was proportionally the same for all four absorbance peaks whereas when trimethoprim was added at the other concentrations, the pigment formed showed a relatively greater increase in the higher wavelength peaks. At a concentration of $15 \mathrm{mg} / \mathrm{L}$, pigment absorbance peaks at 455 and $435 \mathrm{~nm}$ were smaller, but that at $520 \mathrm{~nm}$ was unchanged. When the $520-\mathrm{nm}$ peak was increased relative to the lower wavelength peaks, pink pigment was present, whereas an orange pigment was formed when the reverse obtained. No pigment was produced when trimethoprim $10 \mathrm{mg} / \mathrm{L}$ replaced starch in the extractor fluid (table III).

Concentrations of glucose above $2 \%$ and up to $8 \% \mathrm{w} / \mathrm{v}$ increased pigment yields, but in glucose concentrations above $8 \% \mathrm{w} / \mathrm{v}$, less pigment was formed, the decrease being particularly marked in the lower wavelength components (table III). Late exponential and early stationary-phase cells produced more pigment than did cells from early exponential-phase cultures. Cells harvested in the earlier phases of the growth cycle produced a pink pigment that also showed a relatively higher

Table II. Haemolysin formation by cells of group B streptococcus strain NCTC 8017 in standard* and modified extractor solutions; effect of incubation time and $p \mathrm{H}$

\begin{tabular}{lcc} 
Conditions of extraction & $\begin{array}{c}\text { Final } \\
p \mathrm{H}\end{array}$ & $\begin{array}{c}\text { Haemolysin } \\
\text { titre }(\mathrm{HU})\end{array}$ \\
\hline $\begin{array}{l}\text { Standard procedure* for (min) } \\
5\end{array}$ & $6 \cdot 8$ & 360 \\
15 & $6 \cdot 4$ & 480 \\
30 & $6 \cdot 1$ & 920 \\
45 & $5 \cdot 9$ & 980 \\
60 & $5 \cdot 7$ & 980 \\
Substitution of 0.01M for 0.06M PBS ; & \\
incubation for (min) & & \\
5 & $6 \cdot 0$ & 230 \\
15 & $5 \cdot 3$ & 475 \\
30 & $4 \cdot 3$ & 400 \\
Initial $p$ H of extractor (30 min extraction) & & \\
$7 \cdot 8-7 \cdot 0$ & $\ldots$ & 920 \\
$6 \cdot 6$ & $\ldots$ & 820 \\
$6 \cdot 2$ & $\ldots$ & 450 \\
& & \\
\hline
\end{tabular}

* Standard extractor solution: PBS $0.06 \mathrm{M}, p \mathrm{H} 7 \cdot 0$ containing $1 \%$

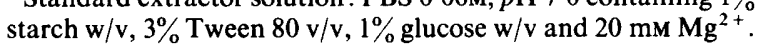


Table III. Pigment formation by cells of group B streptococcus strain NCTC 8017 incubated in different extractor solutions

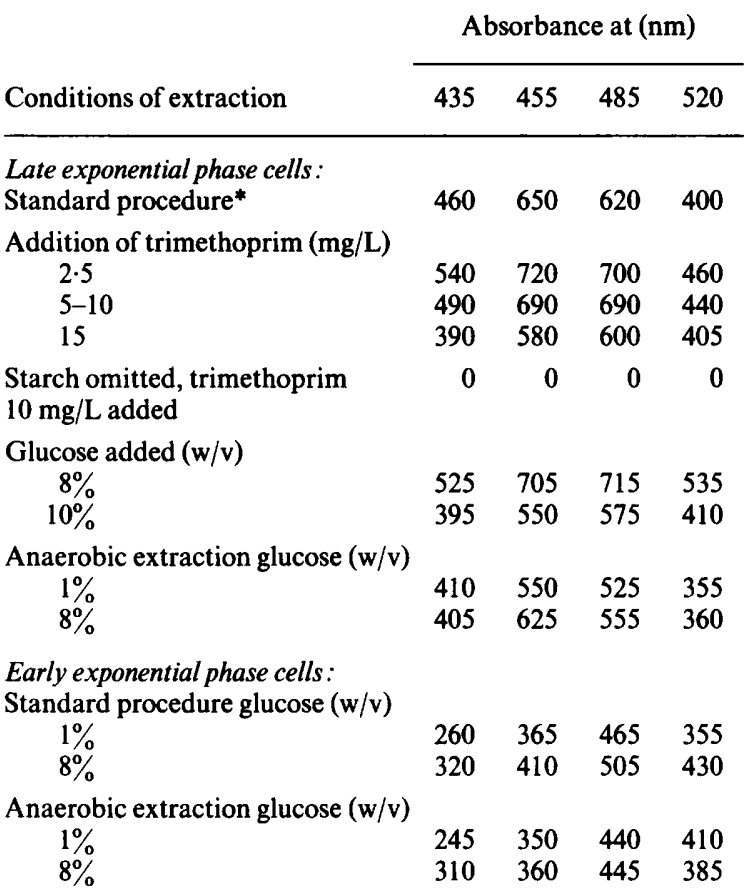

* Standard procedure: extraction in air at $37^{\circ} \mathrm{C}$ in PBS $0.06 \mathrm{M}$, $p \mathrm{H} 7.0$ containing starch $0.1 \% \mathrm{w} / \mathrm{v}, 10 \mathrm{mM} \mathrm{Mg}{ }^{2+}$ and glucose $1 \% \mathrm{w} / \mathrm{v}$.

absorbance at $520 \mathrm{~nm}$. In contrast, an orange pigment was formed by cells from the late exponential and stationary phase cultures; this pigment showed relatively higher absorbance at the lower wavelength peaks than at the $520 \mathrm{~nm}$ peak (table III). In anaerobic conditions, less pigment was produced but its four absorbance peaks were in the same relative proportions as those of pigment produced aerobically.

\section{Relationship between haemolysin and pigment}

Pigment was not a carrier for haemolysin. Extractor solutions containing either four-peak or single-peak pigment showed no increased haemolysin activity compared with control solutions, and significant haemolytic activity, in this series of experiments, was detected only in the extractor solution containing starch and Tween 80 .

When six strains of group B streptococci were ranked by the amounts of haemolysin each produced, the ranking applied also to their capacity to produce pigment (table IV). Measurements of all four absorbance peaks graded the six strains in the same order, although the four absorbance peaks of the pigment formed by the different strains differed proportionally. Strain NCTC 11360 formed a pigment which was pinker than that found by the other strains and had a relatively higher absorbance at $520 \mathrm{~nm}$ than that from the other strains.

\section{Discussion}

There are certain similarities between the ability of group B streptococci to form a caretenoid-like pigment and their haemolytic properties on blood agar. These relationships were explored because it has been suggested that both the pigment and the haemolysin may be virulence factors in group B streptococcal disease (Nemergut and Merritt, 1983; Wennerstrom et al., 1985). It has been shown previously that, in appropriate conditions, washedcell suspensions of group B streptococci form both haemolysin and pigment by an active metabolic process (Marchlewicz and Duncan, 1980; Tapsall, 1986). In this investigation additional common requirements for the formation of these two products in vitro were established. Thus, increased amounts of haemolysin were formed in the presence of $\mathrm{Mg}^{2+}$, an effect noted also with the production of pigment, and less pigment and haemolysin were obtained as the $p \mathrm{H}$ of the extractor fluid fell or in anaerobic conditions. In buffer of increased molarity, haemolysin production continued for much longer than observed by Marchlewicz and Duncan (1980).

These observations coincidentally established conditions whereby maximum yields of a haemolysin preparation were obtained, these yields being well in excess of those obtained in earlier studies (Marchelewicz and Duncan, 1980). These findings

Table IV. Pigment and haemolysin production by washed cell suspensions of six strains of group B streptococci

\begin{tabular}{|c|c|c|c|c|c|}
\hline \multirow[b]{2}{*}{ Strain } & \multirow{2}{*}{$\begin{array}{l}\text { Haemolytic } \\
\text { units }\end{array}$} & \multicolumn{4}{|c|}{ Absorbance at (nm) } \\
\hline & & 435 & 455 & 485 & 520 \\
\hline NCTC 8017 & 920 & 460 & 650 & 620 & 400 \\
\hline NCTC 11360 & 915 & 360 & 445 & 585 & 400 \\
\hline 3321 & 880 & 260 & 350 & 335 & 175 \\
\hline 3 & 760 & 240 & 330 & 315 & 160 \\
\hline $\mathbf{B}_{1}$ & 180 & 90 & 115 & 120 & 30 \\
\hline NCTC 8020 & 0 & 0 & 0 & 0 & 0 \\
\hline
\end{tabular}


enabled a quantitative comparison of pigment and haemolysin production by group B streptococci to be performed. The quantities of pigment produced by several group B streptococcal strains correlated with the capacity of the same organisms to form haemolysin. This finding demonstrated a closer relationship between the formation of these two products than previous studies. Noble et al. (1983) had noted in an epidemiological study that nonpigmented strains were usually also non-haemolytic. The simultaneous loss of both products has also been recorded (Lancefield, 1934; Wennerstrom et al., 1985). The possibility that the pigment acts as a carrier for the haemolysin was explored because of these newly established parallels between pigment production and haemolysin. However, such a relationship was not demonstrated in this investigation.

It was also shown here that both the pigment and the haemolysin are formed throughout all phases of the growth cycle. Although maximum yields of both products were found with cells harvested during the mid exponential and early stationary phases of growth, significant amounts of both substances were detected both early and late in the growth cycle. The presence of both products in all phases of growth would be expected if these substances are, as suggested, protective or virulence factors for the organism in group B streptococcal disease.

The ability of trimethoprim to increase the yield of pigment was also confirmed. It has been suggested (de la Rosa et al., 1983) that trimethoprim

\section{REFERENCES}

de la Rosa M, Villareal R, Vega D, Miranda C, Martinezbrocal A 1983 Granada medium for detection and identification of group B streptococci. Journal of Clinical Microbiology 18: 779-785.

Lancefield R C 1934 Loss of the properties of hemolysin and pigment formation without change in immunological specificity in a strain of Streptococcus haemolyticus. Journal of Experimental Medicine 59: 459-469.

Marchlewicz B A, Duncan J L 1980 Properties of a hemolysin produced by group B streptococci. Infection and Immunity 30: $805-813$

Merritt K, Jacobs N J 1978 Characterization and incidence of pigment production by human clinical group B streptococci. Journal of Clinical Microbiology 8: 105-107.

Nemergut R A, Merritt K 1983 Neutralization of oxidative killing by group $\mathrm{B}$ streptococcal carotenoid pigment. triggers the metabolic pathway for pigment synthesis. It was shown here that trimethoprim does not act as a carrier for pigment. In contrast to its action on pigment formation, trimethoprim did not have a stimulatory effect on haemolysin formation. Similarly, the increase in pigment yield seen with higher concentrations of glucose was not accompanied by an increase in haemolysin titres.

Qualitative differences were noted in pigment produced by cells harvested in different phases of growth, suggesting that several different components make up the group B streptococcal pigment. Differences in pigment composition were also seen when the glucose content of the extractor solution was increased and in the presence of higher concentrations of trimethoprim. Pigments of different hues and different proportions of the component absorption peaks were also produced by different strains of group B streptococci. In pigment obtained in anaerobic conditions, the four absorbance peaks were present in the same ratio as in pigment formed in air, which eliminates the reducing effect of glucose as a cause of this phenomenon. Many bacterial pigments are mixtures of different compounds (Taylor, 1984) and this would appear to be the case with group B streptococcal pigment also. The significance of the appearance of different pigments in different conditions is unknown.

Dr G. Colman of the Streptococcal Reference Laboratory, Central Public Health Laboratory, Colindale, kindly serotyped the group B streptococcal strains used in this study.

Abstracts of the Annual Meeting of the American Society for Microbiology, $\mathrm{p} 28$.

Noble M A, Bent J M, West A B 1983 Detection and identification of group B streptococci by use of pigment production. Journal of Clinical Pathology 36: 350-352.

Tapsall J W 1986 Pigment production by Lancefield group B streptococci (Streptococcus agalactiae). Journal of Medical Microbiology $21: 75-81$.

Taylor R F 1984 Bacterial triterpenoids. Microbiological Reviews 48: $181-198$.

Tsaihong J C, Wennerstrom D E 1983 Effect of carrier molecules on production and properties of extracellular hemolysin produced by Streptococcus agalactiae. Current Microbiology 9: 333-337.

Wennerstrom D E, Tsaihong J C, Crawford J T 1985 Evaluation of the role of hemolysin and pigment in pathogenesis of early onset group B streptococcal infection. In : Kimura Y et al. (eds) Recent advances in streptococci and streptococcal diseases. Reedbooks, Bracknell pp 155-156. 